\title{
Knowledge Economics: Summary and Rationality
}

\author{
Bhekuzulu Khumalo \\ Private Researcher, Toronto, Canada \\ Email: bhekuzulu.khumalo@gmail.com
}

How to cite this paper: Khumalo, B. (2017) Knowledge Economics: Summary and Rationality. Modern Economy, 8, 1533-1560.

https://doi.org/10.4236/me.2017.812102

Received: November 21, 2017

Accepted: December 16, 2017

Published: December 19, 2017

Copyright $\odot 2017$ by author and Scientific Research Publishing Inc. This work is licensed under the Creative Commons Attribution International License (CC BY 4.0).

http://creativecommons.org/licenses/by/4.0/

\section{c) (i) Open Access}

\begin{abstract}
It will be shown that a satisfactory way to look at an economy is to understand the concept of energy costs and use knowledge, and then appreciation of knowledge economics is at hand. One can then grasp the concepts of knowledge economics as their roots are in the major properties of information to see how knowledge behaves, the concept of time and knowledge that needs to be grasped to appreciate economics, to appreciate a phenomenon of the universe, to appreciate what is happening as some societies develop further and others remain stagnant except for a core elite around government. The paper concludes with a thorough analysis of rationality and utility giving our understanding of information and probability, and how rationality allows us to view economic models from the view of knowledge economics giving the properties of information. Our view of economics significantly determines how we treat others; thus our view of economics must be made with all the available information.
\end{abstract}

\section{Keywords}

Algorithm of Information, Categorization of Information, Choice, Commodified Information, Economic Costs, Knowledge Economics, Rationality, Time

\section{Introduction}

There is now enough information to summarize the key factors that one needs to comprehend before understanding and appreciating knowledge economics. We first need to appreciate what knowledge and economics are. Veblen, who existed before the modern computer, was a man who profoundly understood knowledge. He understood societies, and his contributions have been well cited in works that this paper shall cite. Knowledge economics is being summarised from 
the limited sources pertaining to the subject, understanding that knowledge is information; knowledge economics deals with commodified information, and economics can only deal with commodified information. If one wants to see the road to this paper, they should read the references of this paper and see how those papers came to be.

In the late 80's there was a lot of music in the minds of many artists; they would release double albums, and in this paper, one could consider it a double album. Section 7 alone on rationality would be enough, but we need to know where Section 7 comes from. One could read Section 7 about rationality and completely understand it without ever having read the other sections but they would not know where it comes from. Just as one would appreciate the other sections without ever having read Section 7, the algorithm of information can ever stand alone as a critical point of knowledge.

With knowledge being information, we are dealing with properties of the biggest phenomenon possible, a persistent language throughout information, based on the properties of information, consistent with the properties of information. By the time we reach the algorithm of information, the basic principles of how information works and how this affects our view of economics, we must be able to visualize the flow of information, and economics is just a flow of information. Though simple, the basic algorithm of information must have nothing that can be outside it, and thus we recognize the role of probability in economics and conclude with an analysis of rationality.

We must recall what knowledge and economics are before even contemplating defining knowledge economics.

\section{Knowledge}

Knowledge is defined by dictionary.com as:

A) acquaintance with facts, truths, or principles, as from study or investigation; general erudition: knowledge of many things.

B) familiarity or conversance, as with a particular subject or branch of learning:

A knowledge of accounting was necessary for the job.

C) acquaintance or familiarity gained by sight, experience, or report: a knowledge of human nature.

D) the fact or state of knowing; the perception of fact or truth; clear and certain mental apprehension.

E) awareness, as of a fact or circumstance:

He had knowledge of her good fortune.

F) something that is or may be known; information:

He sought knowledge of her activities.

G) the body of truths or facts accumulated in the course of time.

What can be clearly seen is that knowledge has to do with facts that are known. To know these facts, one needs to be informed about them, you cannot know something unless you are told, every piece of knowledge in the entire hu- 
man knowledge base came about because it was told to somebody, somebody was informed, and thus knowledge is information.

At first glance, the statement that every piece of knowledge in the entire human knowledge base came about because somebody was told seems debatable, what about discoveries, who told them? To be told something is to be informed about something, to be informed is to be given information. If one goes to an island where no human has ever stepped on, and sees a flower that no human has ever seen, he tells other humans, who told him about the flower? By looking at the flower and realizing the flower is different, the flower informed him it was different

What about a computer, a microchip, such a discovery by Jack Kilby and Robert Noyce [1], Kilby's discovery being a more important critical point of knowledge as a microchip need not necessarily be from silicone, who told Kilby? Through centuries of discovery, Kilby could see that if you organize material in such a manner you get a microchip, the material told Kilby it is what he termed a microchip by behaving the way it did.

Take a chef, to discover a great dish takes a lot of trial and error usually, each dish informs him/her of its taste through the tongue. Everything is information because everything informs us what it is [2]. At the deepest understanding everything is information because everything is made up of the same stuff so to say. Everything is made up of basic particles, we get differentiation because of the way the information is organized.

If everything is information, knowledge is what we have been informed about. Knowledge is therefore that part of the larger concept of information that is known to us, it can never be false.

Knowledge economics comprises of two words knowledge and economics. What is the relationship between knowledge and economics? To understand this relationship, we must know what economics is. "Economics is the study of how humans use knowledge to identify resources and use these scarce resources to create, using knowledge, commodities and distribute them among people." [3] That is what economics is, one can simplify this to economics as "the study of the flow of commodified knowledge in society" [2].

Having clarified what economics and knowledge are, it is necessary to understand that though everything is information, not everything is identical, a human being is not a galaxy, we therefore need to categorize information for our understanding, to easily recall depending on the discipline.

\section{Economic Categorization of Knowledge}

Commodified knowledge is derived knowledge [4]. Knowledge economics therefore deals mostly with derived knowledge. It is derived from the properties of the material, it is derived from the laws of existence. Though at the end of the day one could successfully argue that all knowledge is a commodity as there is a cost to having it, and that cost at the least is time and this paper will look at time and knowledge in the coming sections. 
Knowledge can be primarily categorized as primary and derived knowledge, note however that it is all information, it all informs us or one can appreciate that we can be told about it by somebody who knows it.

Primary knowledge are the laws of the material, the properties of the thing. These laws determine the pattern of information thus iron behaves differently from water and from humans, we can differentiate things. A primary property of all information is that all information is discrete, otherwise it would be impossible to differentiate anything.

Derived knowledge is knowledge that comes after we have differentiated a thing. Not all sticks are suitable as weapons we know this, the sticks inform us of their properties and we utilize them for our benefit. We know when we organize and manipulate information in a certain manner we get a spear or a computer. It is a matter of rearranging information for our benefit that we get a created commodity. If we did not know the properties of sorghum or wheat they would be worthless in terms of being a commodity, they would not be consumed.

Knowledge can also be categorized in terms of complexity, just as information can be categorized in terms of complexity. Humans have a great ability as information that manipulates other information, one will never find a spoon or a spear in nature, be that spoon wooden or metal. Humans have manipulated information around them to get a spoon, to get a walking stick, to get a spear, reorganized information.

To understand complexity of information, rocket technology offers a good example. "JAXA [5] has been developing LE-9 engine for H3 Rocket, in which high reliability and extremely low costs are required (Figure 2 Left). Its combustion chamber has a double shell structure consisting of the inner cylinder made of the copper $(\mathrm{Cu})$-chromium $(\mathrm{Cr})$-zirconium $(\mathrm{Zr})$ alloy and the outer cylinder heat resistant nickel alloy". Before such alloys could be thought of, copper, chromium, and zirconium first had to be known, thus knowledge of the properties of these metals can be considered primary knowledge, and the alloys derived knowledge, in a sense of categorization of what comes first.

Categorization of any group of things can take many forms, and we understand this from set theory, the same information can be categorized differently according to the discipline. Categorization is a way for humans to simplify information, thus differentiating it broadly, at the end everything is just how basic particles are organized.

From the above mentioned, we have recalled complexity of knowledge from previous papers, but one also must talk of how much energy it took to get that knowledge, but would that be relevant to economics? Perhaps as a judgement of the cost of getting that knowledge, energy expansion represents a cost. Light is everywhere, it was not very expensive for Newton to put a prism in front of a window and see light reveal itself. To prove the existence of the Higgs Boson took far greater amount of energy, a collider consumes a lot of energy. It takes electrical production to get an electrical light, one could write an entire paper on knowledge 
categorized as how much energy it took to get it as well as energy as a cost.

\section{Energy and the Cost of Knowledge}

The concept of cost is central to economics because the production and distribution of commodities (commodified information) is central to the discipline of economics, the very definition of economics attests to this fact. It makes economic sense when the gain is greater than the costs. Costs can be categorized in terms of energy, how much energy does it take to discover something, just how much energy does it take to think, and will the gain in terms of energy in the long run outweigh the amount of energy to conceptualize the new information.

Returning to Newton's discoveries regarding life and proving the existence of the Higgs-Boson, or better still the long-predicted gravity waves. Newton needed a window and a prism to perform his experiments, the prism and glass window took energy to produce, over and above the energy that was used to produce it. The discovery of the prism took energy way back and the countless amounts of energy that went into discoveries that led to the prism. The amount of energy that Newton spent before he came and used the prism to conform his thoughts. A lot of energy is used in creating commodities. What humans spend of themselves is energy, the actual doing and thinking takes calories, so no matter where the calories come from, caviar or roots, it takes the same number of calories to think, that is the reality of information.

In terms of energy the costs are high to get to Newton's experiment with the prism, they are even higher to get to the higgs-boson. All the energy used to get to Newton's experiment, this includes energy spent by those who discovered glass, glass windows, the past thinkers in philosophy and science who discussed light, it is more than just Newton the costs involved. For gravity waves to be confirmed, took such amounts of energy that Newton's discoveries are merely a base in terms of costs in energy, one must add the countless energy for other discoveries that led science to move from Newton's experiment to confirming gravity waves, to confirm the higgs-boson, discovery of electricity, laws of magnetism, radio waves, steam engines, steam engines would provide electricity to do many experiments, and many discoveries. Also, people must include the costs of colliders in terms of energy, billions of calories; all these are costs in terms of energy. What we should realize, the more modern the discovery, the more energy has gone into its discovery, not forgetting discovery of iron takes a great deal of energy to melt the ore.

Energy costs are far more comprehensive than immediate market price as they would include the Pythagoras theorem, how many calories to Pythagoras spend on his mathematics, this does not include energy spent sleeping, drinking, having sex, going to the alter, just the calories spent on his maths are energy costs of the Pythagoras experiment. Did the energy costs of attaining bring a net gain yes, far more information is manipulated than the information transformed to get the theorem, millions of goods depend on the correctness of Pythagoras's 
theorem, net gain.

Understanding that energy is a cost, knowledge policy should always be about the long-term survival of a society, taking care of the short term. Such a policy thus accepts ways that adhere to the laws of knowledge, understanding the role of probability and this probability allows a slightly unique view of rationality, this is discussed last.

The market value of a commodity has very little to do with the total energy cost of that commodity as energy costs must consider historical energy spent, it would seem difficult for the two to have a logical correlation. A simple example in understanding energy is how many calories are spent in getting that knowledge. The costs here are strictly expressed as information, calories, it does not matter how much that calorie cost in market prices, what is important is the number of calories spent. Costs themselves can thus be categorized in several ways, market costs (money), time (how much time did it take to acquire that knowledge) or energy costs.

Energy costs deal "directly" with information. When one talks of calories one is dealing with a physical quantity of information that can be translated as how many basic particles did it cost, where used up to acquire that knowledge concerning a certain pattern of information, to understand that pattern of basic information/particles. Jack Kilby a human being is just basic particles organized in a specific manner, that of a human being, he was an information package. To survive in the form of a human being he needed to take a daily uptake of information packages in the form of food and water, basic particles organized differently. He then manipulates other information organized differently to figure out a microchip, now, how many of those basic particles he up took every day were used in manipulating other basic particles organized differently to think of a micro chip, this is the reality of our existence, disciplines must deal with reality.

To fully understand, how many basic particles did it take for the discovery of a microchip to take place, considering today there are trillions of microchips, one can say that the energy used to discover a microchip was a net gain in terms of energy, we have learnt to manipulate greater amounts of information than is needed to discover how to manipulate that information, nothing is as efficient as a shovel, it has manipulated so much information for our benefit.

The categorization of knowledge has been discussed, this helps us to understand different types of knowledge relevant to economics, economics being the study of commodified information in society. Seeing existence as it is, as the most basic particles organized in different ways, you will see that humans are always exchanging things, a market will always exist, it can never be destroyed, only controlled in different ways because humans will always exchange something. One need not make the mistake of confusing reality with ideological propaganda and avoid making statements like "logically, socialism would be built by eradicating private property, the market, and 'bourgeois' parliaments 
and putting in their place..." [6] Socialism can never eradicate the market, nothing can, one can only control the market in one way or another, how goods get to the people, but as long as goods got to people there is a market. Once things are ideological there is no end to insults one can throw, the author continues "his intellectual horizons were severely circumscribed by primitive theories of class struggle and imperialism" as the authors views about the market are circumscribed in primitive forms of propaganda.

Everything is information, information transforms information because of the relationships that are built, a man transforms oil and creates plastic, -a force, the wind blows down mountains, -a force, black holes pull stars, -a force, different complexities but forces none the less, a transformation has occurred, location of information has changed. That is existence as it is.

\section{Knowledge Economics}

In the paper "defining economics in the twenty first century" [3] knowledge economics was defined "as the study of knowledge, the properties of this resource and how knowledge affects the mode of living". If a definition is a matter of fact, and understanding that knowledge is information, that part of information that has informed us in whole or in part what it is. Mode of living is our everyday existence and is greatly affected by the information that has been commodified, work, factories, transport systems, all these are part of the mode of living. Understanding that knowledge is information, it is not intellectually possible to refute the statement defining knowledge economics.

One must appreciate the previous arguments especially regarding energy. Our mode of living changes with more knowledge we have keeping in mind that knowledge can be divided into primary knowledge and derived knowledge. A car represents knowledge just as much as $2+2=4$, e $=\mathrm{mc}^{2}$, or a spear. Performing the same activity changes with greater knowledge in the performing of that activity, farming with machinery is different from farming with livestock, or by purely human effort. Less people are needed for the activity, they find other activities that will sustain them in the human form, first making sure, they have an enough calorie intake to do activities.

That knowledge is information informs us a lot about the properties of knowledge. To fully comprehend the commodity knowledge, one needs to at least know it is information. Acknowledging knowledge is information that we are aware of, means that the most important property of knowledge is that it is information. Knowledge being information therefore has the fundamental properties of information. To say everything informs us if we can perceive it, detect it. We as human have sensors to perceive information, the five senses keeping it simple. We see, we see another human being, without talking they inform us about many things about themselves. We hear a dog bark, we know it is a dog and by pitch of bark, a fair idea of size of the dog. With the aid of a microscope we can see germs, their shapes and behaviour, and we categorize the germs, 
germs being information. As we build more powerful machines to help our senses detect even the most basic of particles, the more commodities should be expected, and a few believe the most basic of things are still some ways off and this is merely the beginning.

Commodified information is information that we have perceived and commodified for our use, for our benefit. The market is where exchange takes place, paying your mechanic neighbor with beer to look at your car is part of the market, exchange has taken place, remembering and understanding that costs can be categorized in terms of monetary, time and energy.

\section{Benefits of Understanding Everything Is Information}

Since information is everything, any law concerning information is common to all things in existence. "The first law of information, the first law of everything is that every relationship has a loss of freedom. We can put it at its most crude as every relationship has a cost." [7] This applies to everything that exists, if it gets into a relationship there will be a loss of freedom, it does not matter if that relationship is beneficial and creates a more stable structure, what is important is that there is a loss of freedom. This applies as much to humans as to stars and galaxies, all are, and can be described as information packages.

When somebody goes to the store to purchase a packet of chips they are in a relationship with the store owner. Both have lost some degree of freedom, the customer needs chips, and the store owner needs the customer, it is a beneficial relationship as it is a way of distributing a commodity, but there is a loss of freedom. Economics will not betray the first law of everything. The ideological side of economics deals with the question, there is a loss of freedom, but there is a benefit, how best do we maximize this benefit whilst minimizing the loss of freedom?

One could easily retort, what about the lion and the zebra? They are in a relationship and the zebra is always on the losing end. A predator and prey relationship is only beneficial to the predator. What humans know is that when wolves were reintroduced to Yellowstone National Park in America there was tremendous environmental benefits, "the reintroduction of wolves continues to astonish biologists with a ripple of direct and indirect consequences throughout the ecosystem" [8]. The economist must be aware that economics in many aspects follows the laws of information a relationship it shares with all other disciplines.

The second law of information "an information package will remain in its present state unless a relationship is established" [7]. Such simplicity but this immediately explains development economics, if a society is not getting the results that it wants it must change direction, change aspects of its culture, culture is dynamic, one can't hold on to witchcraft, honestly water will never be diesel, that is technology yet beyond our imagination. The laws of knowledge are known, everything is step by step. The mind is merely an interaction of informa- 
tion, culture is in the mind, the laws of the land are part of that culture. Changing the laws changes the culture, thus the mind. When rationality is discussed we will understand better how humans make choices given what we understand about information.

When we accept it is all just information and that with increasing knowledge our mode of living changes, it would not be unreasonable to expect that the knowledge base of a society increases over time. Time is a constant, we know a year is just over 365 days. But the effects of time need not be constant, time too can be categorized and must be for knowledge economics to be fully appreciated.

\section{Time}

What is time? When we talk of time we are not talking of the times, but the passing of seconds, hours, days, years, decades, that is time. We can say time is a rhythm, a day will always be 24 hours. It is a rhythm outside human control otherwise we would all have different times and indeed we all have different times. This can be seen culturally, if one has ever lived in rural Africa, perhaps Southern Africa, when one asks how far are the cattle, one would be told at a steady pace they will find the cows when the sun is so high in the sky, say midday, meaning one will get there at midday. What has happened when one gets there after the sun is at midday. Humans all have a different pace, a different rhythm, thus time being different if we used human rhythms as a standard for time, time would be different for everybody.

That humans have different rhythms of time allows us to make a crucial mistake concerning time and economics. When one reads economic books on development, one of the first impressions one gets is that somehow some countries are backward, behind the times. When one says somebody is behind the times, that normally means the times are too fast for them and they are not changing with the times. Backwardness implies slow. The way economists look at developing countries is the way urban people look upon rural people, not with the times, the times are too fast. With such a common cultural background one ignores the evidence and concludes that time is somehow faster in developed countries or urban settings. That is so far from reality.

The Variable Time [9]: Crucial to Understanding Knowledge Economics it was concluded that "the slower time seems to be moving the more knowledge shall be gathered". This is simply because more work has been done. We can look at time as a rhythm with knowledge, let us say every unit of time 1 unit of knowledge, a knowledge is gained.

From Figure 1 we can see the algorithm of time and knowledge. An algorithm is a way of understanding what is going on, it is a tool, a useful tool. The above algorithm is very simple but of course if one decides to, they need not to understand the concept of time and knowledge, but if they desire, they can see that at the last yes, that time has slowed, and more work has been done, the next question will be how much knowledge was gained, and by how much knowledge was gained, and the algorithm will assign how much time has slowed by. 


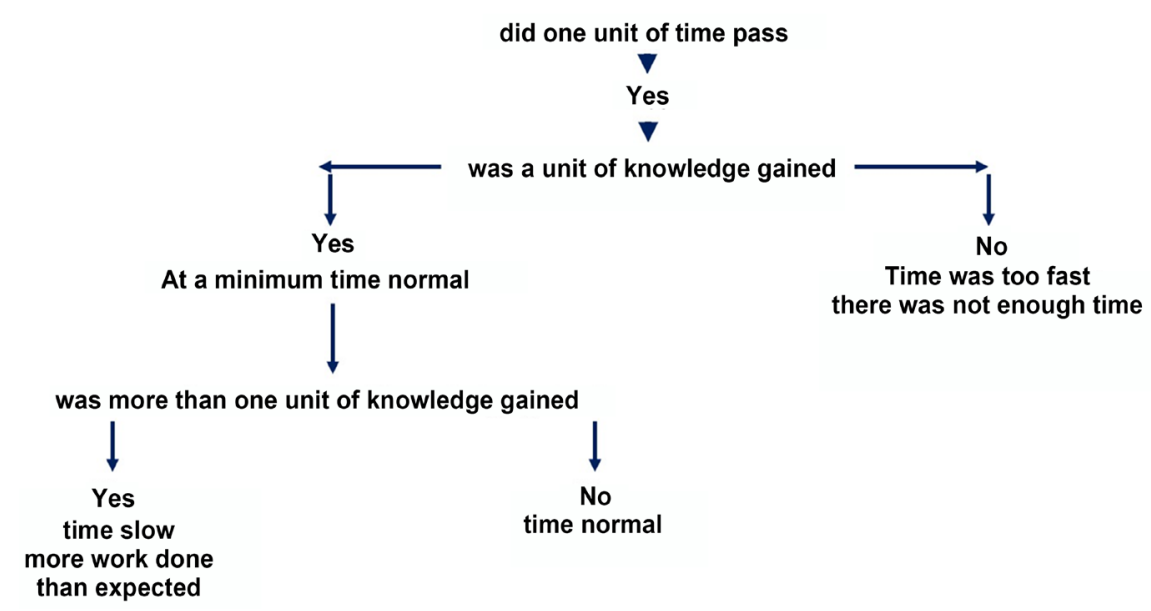

Figure 1. Algorithm of time and knowledge.

Understanding that there are many possible paths one can take to reach the same conclusion when it comes to knowledge, probability is pervasive throughout existence and should form a great deal of our view of existence. For some, the algorithm of time leads to a far bigger picture, that if time can be expressed as an algorithm, then information can be expressed as an algorithm remembering the crucial law of knowledge and therefore information, the law of consistency.

\section{Algorithm of Information}

All information is discrete, being the same is not a qualification for continuity, all information is discrete. Because all information is discrete all information is independent, though one comes from their mother and father, one can never be their mother and father. No two basic particles are the same no matter how similar their behaviour, they can never be the same. No two pieces of information can ever occupy the same space, all location is unique, because all information is discrete and therefore independent. One cannot be the store owner and the customer at the same time, impossible no matter how much one takes a pack of chips and pays oneself, reality does not double count, it's just a good way of keeping the business afloat.

Accepting the above one can then postulate in a manner that allows simplification, what if existence has its roots in only two pieces of information $x_{1}$ and $x_{2}$. This simplifies what could otherwise be an extremely complex algorithm. This is illustrated in Figure 2. The algorithm of information can be called konke, meaning everything in Nguni languages.

As one can see from Figure 2 the entire algorithm sets about probabilities. The first question, is it $\mathrm{X}_{\mathrm{i}}$, there is so much probability that it is $\mathrm{X}_{\mathrm{i}}$ given the physical proportions of the different types of information packages. The whole algorithm, answers to the simple questions depends on probability. There is no action in the universe that this algorithm cannot answer. 


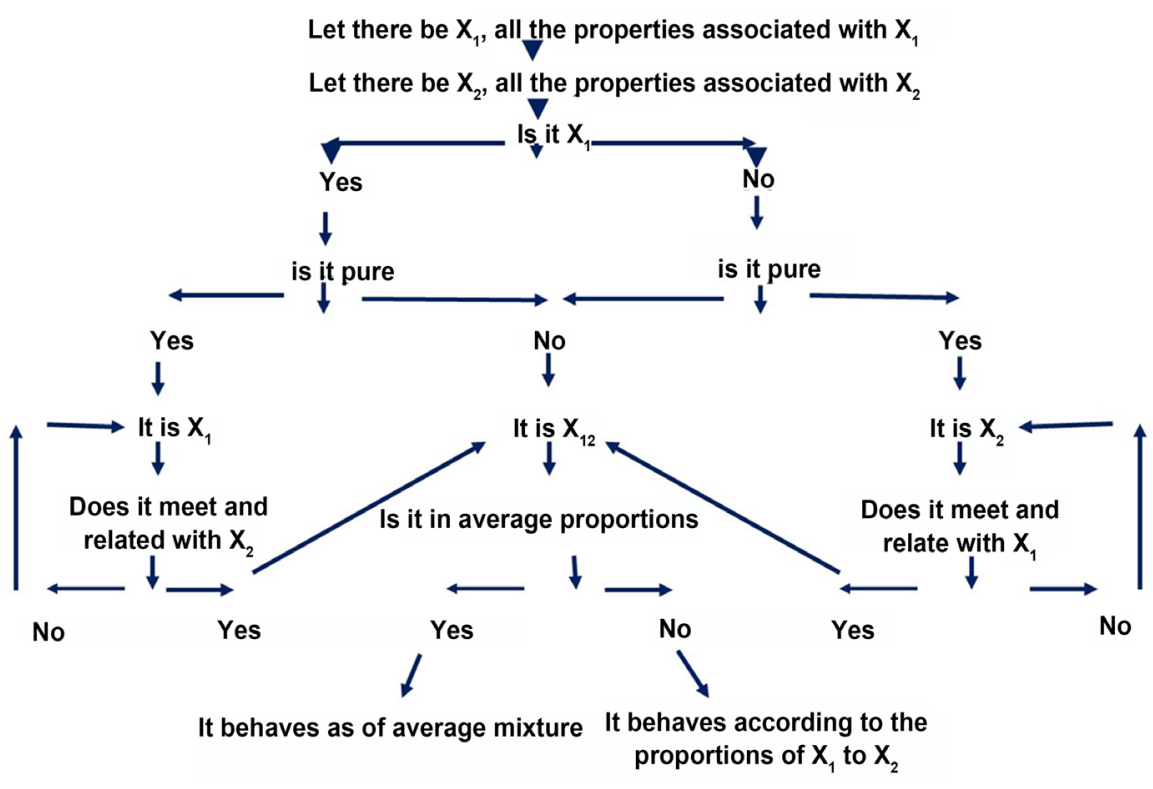

Figure 2. Algorithm of information.

To a philosopher, this algorithm means the universe could very well be considered an answer to a question, we are all somehow answering a question creating relations with everything else, can this be eaten? Can this burn? Can this structure provide good shelter? Is this an ideal partner? The above algorithm of course is merely a skeleton, in it are countless lessor algorithms. For $\mathrm{X}_{1}$ to meet $\mathrm{X}_{2}$ implies there is changes of location, getting into relations need not always be the same hence different proportions are expected, sometimes proportions must always be the same, it will always take 2 particles of hydrogen and one particle of oxygen to make water, but one can unite metals in greater variety to get different grades of alloys/properties.

For the algorithm of information to be understood, one must know that each relationship brings about a unique and different information package than $\mathrm{X}_{1}$ and $\mathrm{X}_{2}$ being separate. The best example to give is always water, oxygen and hydrogen are both gases, but when combined we get water that puts out fires. Iron ore is a completely different material than pure iron. A shopkeeper without customers is very different from a shopkeeper with customers.

The algorithm of information is such that it does not matter how it is designed, however the question of $\mathrm{X}_{1}$ and $\mathrm{X}_{2}$ meeting must be asked, is it $\mathrm{X}_{2.1}$, or $\mathrm{X}_{1.2}$ same thing in this scenario, if yes then we begin to see that the algorithm is merely a skeleton. It is established that it is $\mathrm{X}_{2.1}$, there needs to be a supplementary algorithm that defines the properties of what comes after $\mathrm{X}_{1}$ and $\mathrm{X}_{2}$ get into a relationship. Figure 3 illustrates such a supplementary algorithm.

There is $\mathrm{X}_{1.2}$, now $\mathrm{X}_{1}$ and $\mathrm{X}_{2}$ cannot relate in any manner they want, you cannot have 20 oxygen atoms and 1 hydrogen atom, the laws of existence will just not allow that, there is a predefined way they can meet. These predefined ways are $\mathrm{P}_{\mathrm{i}}$ in Figure 3 above. Thus $\mathrm{X}_{2.1}$ can only exist according to proportions set out by $\mathrm{P}_{\mathrm{i}}$. There is only one way that oxygen and hydrogen can meet, and one 


$$
\begin{gathered}
\mathrm{X}_{1} \text { and } \mathrm{X}_{2} \text { meet } \\
\text { and are in a relationship } \\
\text { there is } \mathrm{X}_{1.2}=\mathrm{X}_{2.1} \\
\text { They can only relate in } \mathrm{P}_{\mathrm{i}} \text { proportions }
\end{gathered}
$$$$
\text { Each } \mathrm{P}_{\mathrm{i}} \text { a unique character that is defined }
$$

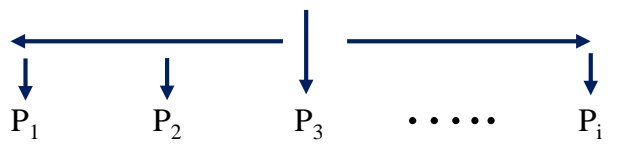

Figure 3. An algorithm of property of information.

gets water, two colours can seemingly meet in seemingly endless proportions/ combinations.

There is one more algorithm to add that will show that the algorithm of information is continuous because it's principles must be repeated over and over. This is illustrated in Figure 4 in what has been called the algorithm of continuity.

As can be seen in Figure 4, the algorithm of information can be reproduced so many times until you have the complexity of a human being, the most complex information package that we have come across and able to manipulate other pieces of information greatly and effectively and efficiently. The wind takes a billion years to wear down a mountain, we can blow it up very quickly, in terms of time extremely efficient in manipulating information. Just by looking at the algorithm of information and the complexity it represents with the universe just being divided into two types of information. The infinite combinations of light with just two colours, think three or four. Besides affecting our economy, the algorithm still functions in us biologically, we are evolving, not yet a stable piece of information in many regards.

Each $\mathrm{P}_{\mathrm{i}}$ is different because different losses of freedom are involved for different ratios of $\mathrm{X}_{1}$ to $\mathrm{X}_{2}$, one can say different costs are involved to maintain the relationship. These costs are best understood as energy. Energy is used to maintain a relationship, both the hydrogen atoms and oxygen atom must use energy to maintain their relationship that is water, that is why water behaves so differently from free oxygen and hydrogen atoms. This applies to economics too, if one wants to drive around in a Bentley their relationship with the dealer costs more than the relationship of purchasing a Honda Civic, one pays many times more for a Bentley than a Honda Civic, this will be appreciated in the next few sections.

Of course, categorization affects demand and supply, core tools in any economic analysis or thought. Probability is everywhere in the algorithm of information, it will be everywhere in economics and there really is no economics without demand and supply. Demand has to do with choices, and choices will always be limited and as long as goods are on the market there is a probability they will be demanded. 


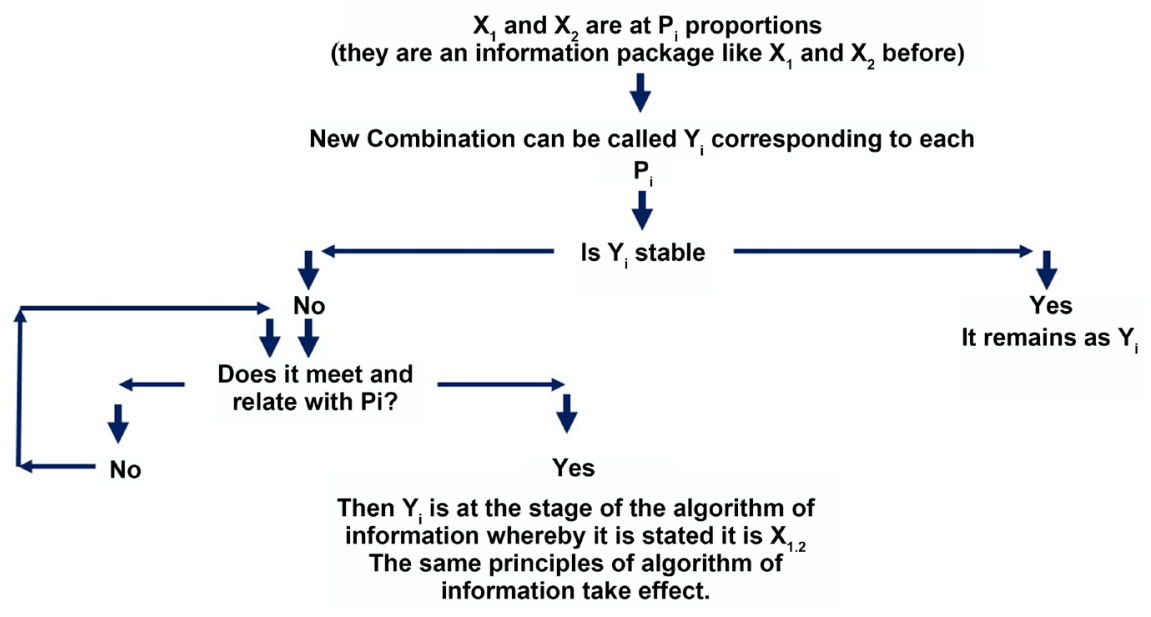

Figure 4. Algorithm of continuity.

Choices are limited though seemingly endless for two colours; choices are limited, as the example of water attests to that. That choices are limited, $P_{i}$ when information gets into relationships is an important factor in economics as well, the players in economics being information packages. Understanding thus far knowledge economics, categorizations of information and costs, and now importance of probability to the algorithm of information, our view of rationality and choice must change in alignment with information.

\section{Utility, Choice, Rationality and Information}

Essentially all decisions made include elements of utility maximization. Decisions are made in all life's aspects not just economics. When it comes to decisions in economics, these decisions are around choices made around goods and services. Human beings are confronted with choices that need decisions to be made daily, should one make a left turn, should one buy a pizza, the principle behind all the choices is the same, maximization of utility, making rational decisions, decisions that will bring about a benefit, a desired outcome.

Utility is a central feature and core principle of modern economic analysis, how society is to be organized such that the society may maximize its utility. This utility of society is maximised when the sum of individual utility maximization efforts allows the society to progress.

Choice is the principle behind utility maximization, what choices will result in maximization of utility of the individual. Individuals make choices that are best for them at that moment given their desires in life. Each choice represents a different path in life for the individual and a different path for society. For example, the idea that there are three brands of motor vehicles available, depending on the choice one makes on purchasing a vehicle, resources of the society will go to either of the three manufacturers, the most preferred getting a larger share of society uses to create wealth. The act of choosing not only affects the individual but society, should individuals be forced to make certain choices, this is a key 
socio-economic question? Forcing someone to make a choice is to choose what is rational for them, is this ethically and morally correct?

That choices must be made means that human beings are behaving like all other information. It is when we tally our choices that we see the similarity with all other information, further cementing the idea that economics is a science and all other disciplines are also considered sciences. To appreciate this discussion, one needs to first acknowledge the fact that choices can only be made by knowledge that we posses.

\subsection{Recalling What Utility Is}

Economics at the end of the day is about food on the table. What food is on the table is a matter of choice, even if there are no choices available to take what is offered, is to have made a choice. Because a choice must be made of what to put on the table, should there be ten choices, for example 10 brands of beer are available in the market in society 1 , that means beer consumers have ten choices of beer. In society 2 , only one beer maker is allowed, there is only one brand, beer consumers in this society have only one choice, there is a choice, no matter how limited that choice is. In society 3 , beer is not allowed, the choice to consume beer cannot be made unless there is a black market for beer.

To make a choice implies a preference. Even in society 2 in the paragraph above to make that one choice means to make a preference, one could choose to abstain from that one choice for whatever reason. In society 3 , a choice cannot be made, however those who choose to make a choice to consume beer have made a choice that includes a preference for beer over the legal ramifications. The underpinning theory behind choice is utility theory. As can be seen from discussion around society $1-3$, choice of what to put on the table must be made in every society, by every individual according to what choices are available even if that choice is not there, then the choice is already predetermined. As choice is determined by utility, utility theory affects all humans who must decide what must be put on the table. It must also be remembered that choice is not merely about availability, the average person for example will not spend $\$ 100$ for a six pack of beer. That is ten times the minimum wage just for a six pack of beer, that is 10 hours work for a six pack of beer, therefore choice is also determined by income and many other factors besides availability.

Having mentioned utility thus far and recalling its importance, economics can be said to be a study in part of the satisfaction people gain from what is on their table at dinner time. This is something worthwhile for economists to point out to the politicians that they advise, are people truly satisfied with what is on their table at dinner given factors that determine satisfaction, an ever-changing function satisfaction given ever changing understanding of information, our ever-increasing knowledge leading to ever more sophisticated products. We need to ensure that all are on the same page, that is why references like dictionaries are important, this will ascertain we understand that all are on the same concept 
of utility given that this is an economics discussion.

As utility theory is the cornerstone of understanding choice in current economic thought, what does utility determine, what is choice? According to dictionary.com choice is "an act or instance of choosing; selection". So that we are clear about what we are talking about the same site defines choosing as "to select from a number of possibilities; pick by preference". Utility theory therefore helps us understand how a choice is made.

A choice is made at a moment, the act of choosing is made when a choice is made, a choice is made only when an action is taken. The thought of taking that action might have taken several hours of thinking, or maybe years, but the choice is only made when an action is taken. The choice to overtake another car on the highway is only made when the other car is over taken. Utility theory is about choice, a choice is not only made when we decide what brand of beer to consume, but even when we choose to overtake another car on the highway.

A choice therefore is made now, the strongest influence must be events before the moment, a suicide bomber technically is not a suicide bomber until the button is pressed, not everybody goes through with the process. The choice to gamble is made when money is put on the table, at that moment, gambling is a solution to something, instant fortunes are always alluring, instant fortunes have been made, look at all the lottery winners, the possibility exists. As choices are made in the moment utility theory at best does not answer questions of rationality and cannot answer questions of rationality, what is rational at the moment the decision is made, a whole host of factors come into play. The act of deciding is the same for all choices, this is noteworthy. When a worker loses his job, and goes on a shooting rampage, a decision is made to go on a shooting rampage. When one decides to buy a beer, a decision is made to purchase that beer. In both instances, a decision is made that satisfies a need at that moment otherwise the action would not be taken, all decisions satisfy the moment. A prisoner under torture may decide to lie to end the torture, at that moment being broken satisfies the needs. Choice is made to maximize utility at that moment. That choice might yield long term profits or short-term profits with long term loses, but at that moment, a person felt that is best decision to make, best choice to make for whatever reasons, but at that moment it must have maximized their utility otherwise the decision would not have been made.

Understanding choice, we should understand the first law of everything because choices at the end of the day are about relationships, all choices are about relationships. We know from the first law [7] of everything that every relationship has a cost, every choice therefore involves some cost. The word cost here is a neutral concept, it means energy must be spent to sustain the relationship, the basic cost in all relationships must do with energy. Spending time doing an activity takes energy, all choices made in life take energy in one way or another.

Take the act of purchasing a television or any other commodity, one pays in money or other forms, but usually money in this period. To earn that money takes time doing a certain activity and one is given a reward for doing that activ- 
ity. That money represents earnings for spending one's energy doing a certain activity. It took energy to earn that money and it is spent on commodities. It also took energy to create those commodities. Purchasing a beer or a television implies a relationship and one is gaining from that relationship even though a cost has incurred. Cost when talking in the language of information has no positive or negative connotations, it merely means energy was spent. A paragraph to recall why all relationships have a cost we can have a paragraph to recall what was explained in the presentation "Information, Knowledge, Economics, and Technological Progress" [4].

Everything is information and it is this that makes economics a science, this was explained in the paper "why economics is a science: Information the grand unifier" [2]. Economics is a science because it deals with the extraction of information. Everything is information in simplest terms because everything informs us about itself. All information has basic characteristics that are common to all information, all information can be isolated, it is all discrete, and independent of other information, it exists because of the laws of existence, the laws of nature if this then that. For everything to exist is in a relationship be it a husband and wife in a marriage, electron in relationship with protons and neutrons, lions in relation with their prey, lions in relation with each other, a rock in relation to the mountain, the stars in relation with other stars and planets around them, all these relationships have a cost, they take energy to maintain. It takes energy to maintain a relationship with beer, or any other consumable commodity, you must spend energy to get it, humans are information and the beer is information, information organized in different patterns.

All choices represent a direct cost over and above the opportunity cost associated with that choice. Opportunity cost is how one could have used the same amount of energy doing a different activity, the cost associated with the relationship is the actual amount of energy spent on that activity. That a choice to undertake an activity represents how to spend ones' energy, how to spend one's time, utility theory is about understanding how one chooses their relationships, how one makes a choice.

\subsection{Utility and Rationality}

A choice is made only at the moment an action is taken. Even pre-determined murder is not murder until the trigger is pulled. It is only when the trigger is pulled can we say a decision has been made, a choice has been made, and at that moment the choice was the best choice the human could think of, balancing long term issues and short-term issues. To allow this to sink in let us look at an example of buying a car, one can plan the decision for months, saving for 2 years and thus having a good down payment and less interest to pay, versus scenario 2 , a guy with no savings but a good paying seasonal job on the spur buys the same car, the choice itself is made when the cash is handed over, what is rational or what is not, utility theory cannot answer that, it can only say at the moment the cash was handed over, for whatever reason that was the best decision to make, 
otherwise the action would not have taken place. This means the best decision at times may seem irrational, how can one leave, love and certain luxury, but maybe at that moment one realises different things for whatever reason, maybe some job must be finished, perhaps one has set off to discover endless energy, there is love everywhere if one tries, but endless energy is a difficult concept.

Because choices are made at the moment, it is impossible to judge their rationality, a mistake made and rightly attacked. Utility theory merely states a decision has been made and it must yield the highest utility otherwise the decision would never have been made. The reality of a decision being rational or not can only be determined in the future, therefore the idea of rationality is a probability function. Utility theory can only talk of a decision that has been made, not the future, rationality can only be determined in the future.

Two individuals $\mathrm{A}$ and $\mathrm{B}$ purchase $\$ 5000$ worth of shares in a new mining venture, very risky, but if they find the mineral that investment is multiplied 100 times. A's net worth is $\$ 5,000,000$, the loss would not be so great as compared to $\mathrm{B}$, whose net worth is $\$ 50,000$. Who is rational, at the moment the decision is made one cannot know. In the future, if the investment fails then A was rational, and B was not, however if the investment proves a success, both are to be considered rational. Though rationality can be determined only after the choice is made, risk can be determined before the choice, the two are not the same risk and rationality, most entrepreneurs have a bulk of their investment in one industry, their company.

If one robs a bank, the rationality of the act depends on the success of the choices. Society tries to make robbing banks as difficult as possible so that the chances of a rational outcome if one robs a bank is minimized thus bank robberies are minimized to the riskiest of folks. We know from history terrorists often end up ruling countries. If they fail they are irrational, if they succeed they are rational, many factors play into a choice, nobody knows the future, utility theory deals with at best risk, never rationality. Colonialists made it risky to fight imperialism, but it turned out to be the rational thing to do, besides the morality of the anti colonial fighters. Rationality has nothing to do with morals, a moral argument has nothing to do with a rational argument.

\subsection{Maximizing Utility}

The idea of a human being is to make the best choices to survive first of all. What can be considered a normal human being, normal is more than the average, when talking of normality, one must at least be talking of a minimum 95\% of the population. Sri Lanka in 2015 had the highest suicide rate in the world [5], 34.6 per 100,000 , that is $0.03 \%$ of the population. More than $99 \%$ of the population in the country with the highest suicide rate want to survive, the normal person wants to survive. Life is maximizing utility for most human beings, all other decisions come after one has taken care of life to be able to make those other decisions. 
Having taken care of life, maximising utility must do with extrapolating the past and hoping outcomes will come out in a similar way. When one purchases beer, they expect the same gain as the last time they purchased beer, if they find a rat in a bottle they will not be happy, strange things have entered bottles and tins. If one finds beer is flat, is the act still rational, how can it be, the justification of taking the action is not fulfilled, the beer will not be consumed. It is therefore more meaningful to talk of an expected rational result from the choices one makes rather than saying a rational decision has been made, that is impossible.

If the question of rationality of a choice can only be made in the future, then the very act of maximizing utility is one taking chance choices made will turn out as favorable as expected in the future. Purchasing gold is a rational decision if inflation occurs in the future, if inflation does not occur it is not a rational choice to have gold in one's portfolio. Rationality cannot occur at the moment the choice is made, if that was the case, then people who invested with con artists like Bernie Madoff could have been considered to have been rational to have invested with him, the reality in the future far after the decision was made to invest with a con artist like Bernie Madoff showed such a choice was irrational, people missed something when they made their choice.

Maximising utility therefore entails making decisions that yield a positive outcome in the future. Therefore, whenever we talk of maximization of utility, it is always the expected maximum utility since we shall consume that good, the apple could be rotten. Does a model of maximization of utility, that is what economics is about the maximization of utility, should such a model incorporate the idea of rationality, can it incorporate the idea of rationality?

As we can only know something is rational in the future, the idea that one makes a rational choice is wrong, the idea that one has had a rational outcome because of past choices is correct logic provided the outcome is what one wanted. Models based on rational choices are wrong, Bernie Madoff is a clear example, he presented himself as what people considered a financially rational person, and people fell for it. The idea of rationality is a probability function in the choices we make. There is the reality that in the future the choice could turn out to be rational or irrational. Casinos understand this, they make fortunes on choices that usually turn out to be irrational. If the choices where mostly rational casinos would go broke. Rationality is never guaranteed.

\subsection{What Is Rationality}

What we can be certain of is that rationality has something to do with choices made, beyond that, answering this question is difficult. The word rational is defined by dictionary.com with several meanings that are all similar and all relevant except in this instance the mathematical definition:

1) agreeable to reason; reasonable; sensible:

a rational plan for economic development.

2) having or exercising reason, sound judgment, or good sense: 
a calm and rational negotiator.

3) being in or characterized by full possession of one's reason; sane; lucid:

The patient appeared perfectly rational.

4) endowed with the faculty of reason:

rational beings.

5) of, relating to, or constituting reasoning powers:

the rational faculty.

6) proceeding or derived from reason or based on reasoning:

a rational explanation.

7) Mathematics.

a) capable of being expressed exactly by a ratio of two integers.

b) (of a function) capable of being expressed exactly by a ratio of two polynomials.

The first definition, is on spot, this is what most of us think of as rationality, and as one can see, the definitions are basically the same, agreeable to reason, reasonable, thus a rational choice is a reasonable choice. The concept of reasonable is different to different societies. Take 2 societies, 1 and 2, both societies have as their main carbohydrate supply being bread, however they have different degrees of freedom in the two societies. In society 1 there are 7 brands of bread one can choose to buy, the idea of rationality says for a consumer, given their circumstances, what is the best brand to choose out of the 7 , which of these brands will likely yield a rational decision in the future.

In society 2 , it has the same number of people as society 1 , however they only have one brand of choice of bread. Immediately to the perceptive the idea of rationality is different because rationality is about choices, society 1 has more choices than society 2 . In society 1 everybody's choice is the same when it comes to choices of bread, everybody's rational expectations are the same, there is always the choice don't buy the bread, but if you but the bread the rational outcome is the same as everybody's else's. The way society is organized therefore has a significant factor in making choices that will be rational hopefully in the future.

In rational behaviour, priority being the need to survive is determined by how a society is organized, therefore if a society is organized in such a manner that the probability of the individual decisions cannot in total be rational then that society will have a bad future, lots of control. Such states are recognisable, high corruption, from the top to feeling up on gasoline, high corruption means kleptocracy, murder and bribe a cop or the judge, perhaps threaten the judge's livelihood, destroy the lives of witnesses, print money for the corrupt. These might seem like just immorality, but all the immoralities above rob society of choice, the choices are reduced in a society whereby one knows the judges are in some people's pockets. In most instances where there is corruption it limits the choices that people can make that they feel will result in a rational outcome in the future. They must take up secondary choices, sometimes third choices. 
In such societies to get ahead one must be corrupt, but to get ahead is a rational thing to do for most people. Thus, the rational act feeds an irrational act for society. When being corrupt becomes a rational act, the probability of that society moving ahead in terms of the material well being for society, not just the most corrupt, because in the most corrupt of societies everybody needs to bribe the cops at roadblocks, everybody is corrupt, it is just that the more corrupt because of means get ahead merely because they have more resources to bribe. Everybody wants printed money from the Federal Reserve, from central banks, but only a select few get these handouts because they have bigger pockets to bribe.

Rationality is about the future, the corrupt for example always try to defend their corruption and immorality by saying it will be irrational to desire a future whereby you can make choices that will probably have higher greater rationality. As a slave, it is rational to revolt to give your prodigy higher chances off making decisions that yield a more rational future. The concept of rationality is different for different people. In the eyes of the slave owner it is irrational for slaves to revolt because if they are caught they will be tortured and hanged, thus over and above the fear slave masters have of a slave revolt, they feign confusion at why slaves would want to be free when it is obviously irrational in their minds as they believe they have built fool proof ways to enslave a people for ever, civilizations think they are forever, the privileged, owning a slave is a massive privilege, they believe they are for ever, who built the ruins under the sea near India, a proud civilization that believed it would own slaves forever.

To the slaves who have ambitions as a human being, it is irrational to remain a slave and risking one's life must be a possible risk to attain the greater reward of liberty, having choices available that can attain rational results thus maximising utility. The mere act of getting a rational result is maximizing utility, a rational result is the result one expected. It seems that the most rational societies in terms of material gain must allow people to be able to make up their own minds on what is rational, thus giving that society more choices, or at the very least the potential of more choices.

It would not be wrong from our discussion on rationality to say being open to choices means less corruption, one needs not to be corrupted to get ahead, zero slavery, slaves have extremely limited choices, but choices are not limited in a legal and cultural sense. More choices mean individuals can make choices to greater maximize the possibility of making a rational choice that is not harmful to society. For society to maximize its utility it needs to allow individuals to maximize their utility by allowing individuals to have as many choices as possible to enable greater ability to make a rational decision, a rational decision in an economic sense is maximising one's material well being, that need not be a good or service, it could just be time to do yoga, one can't get more material than one's body and mind.

Choice affects everyday living, choices are made to maximize utility, and utility can only be maximized after the choice is made, and it remains a probability. 
Deciding does not mean one will get a desired result, one can decide to go to a girlfriend's house and catch her with somebody else, surely maximization of utility in this case was not attained. One can purchase a pizza and find a rat's tail on it when they get home, it is a probability that making a choice will lead to utility maximization. Probability is a huge part in behaviour of basic information, basic information like basic particles, probability is a huge part of all information behaviour in one way or another.

Choices made concerning goods and services, commodified information, falls under the realm of economics. Choices made concerning military strategy falls under the discipline of military strategy, all choices are made for the same reason, to maximize utility, to have a rational outcome, when it concerns economics a rational outcome is to get satisfaction from consuming a commodity, in military strategy a rational outcome is to win the war, in war, somebody's choice always turns out to be irrational. Choices are always limited, there is not an infinite brand of televisions, cars, chocolate bars, beers, that is just the reality of existence. There is a limited number of ways to get to the place where one's girlfriend resides. There will never be an infinite amount of choices, sometimes choices are merely yes or no, on or off, 0 or 1, many times there is no choice at all. But what one should realize when we look at choices from the perspective of knowledge economics, studying commodified information, one immediately see's that irrationality is not so common at all. In war, there must be a loser, in football there must be a loser, in elections there are losers, irrational choices are everywhere, that's democracy, that's liberty.

\subsection{Limitations of Choice}

Limitation of choices is a universal concept, it is common to all information. This gives structure to information. One cannot be here and over there at the same time. A choice must be made to be over here or over there. One is where they thought they would maximize utility given past choices, it does not mean one is maximizing utility, a rational outcome is always a probability, how can one be maximizing utility in prison? The idea of being here and there at the same time applies to all information, the moon is over there, it cannot be over there and 2 million light years away. If you look for something and find it, be it a photon, or a carrot, it can only be there, where you found it, where else can it be?

Limitations on choice means that there is usually a certain number of choices we can make, in economic terms we understand the number of choices available according to market type. A market that falls under perfect competition will allow society to have the most choices. An imperfect market will allow fewer choices than a perfect market but more than an oligopoly. An oligopoly will offer more choices than a monopoly, and a monopoly will offer the least choices for a commodity. A commodity in an economics sense is anything one pays for.

Take a car market, we can make one up, or one can collect actual data, it's irrelevant in what is being discussed, limitations of choice and how this limitation 
of choice applies to all information. Car market has nine players, the statistician reported the information as set out in Table 1, these are made up.

The figures represented if Table 1 are random events and can be expressed/ estimated as a probability function. All data collected represents a time period. In Table 1 we can say the data is collected quarterly. Even the fastest events dealing with light, the data is created in seconds, but it is not instantaneous. Slow down time and it will take longer to collect the data. Data can often be represented in many ways meaning there are many ways to make an estimation, all that matters is the accuracy of those estimations, this shall be seen as we discuss further.

The data represented in Table 1 can be illustrated graphically as Figure 5.

Being messy is not what makes data represent random events. What makes an event random is that it cannot occur with $100 \%$ certainty. People buy cars to satisfy their utility, the act of satisfying utility is itself a random event because rationality can only be known in the future. What if one in the past did not like the model they bought and will not be a repeat customer. What if between the last time period, could be as long as 15 years ago, a customer who was faithful to model realizes that there are now better models. If things were certain everybody would still be using kodak and polaroid.

Figure 5 can be better organized alphabetically as in Figure 6 .

Figure 5 and Figure 6 can both be organized much neater such that models can make. A nice neat manner of organizing data is from small to large, eye catching as in Figure 7, usually seen with time trends, but is there really another way to show time trends? It is more eye catching than Figure 5 and Figure 6 because there is a clear pattern that the mind can recognize, but this does not make the events less or more random.

Table 1 can also be represented as data organized from large to small, this represents a different model from when data is organized as in Figure 8, but their estimates should be similar. This is laid out in Figure 8, physiologically less appealing as it does not satisfy our ideal of constant growth even though it shows exactly what Figure 7 does, perhaps it is an individual choice.

Table 1. Car model sales.

\begin{tabular}{cc}
\hline Model & Number 000's \\
\hline pol & 1000 \\
loy & 5500 \\
jos & 5000 \\
wus & 1500 \\
oso & 1750 \\
ulu & 6000 \\
pak & 3500 \\
zuv & 3000 \\
uko & 4500 \\
\hline
\end{tabular}




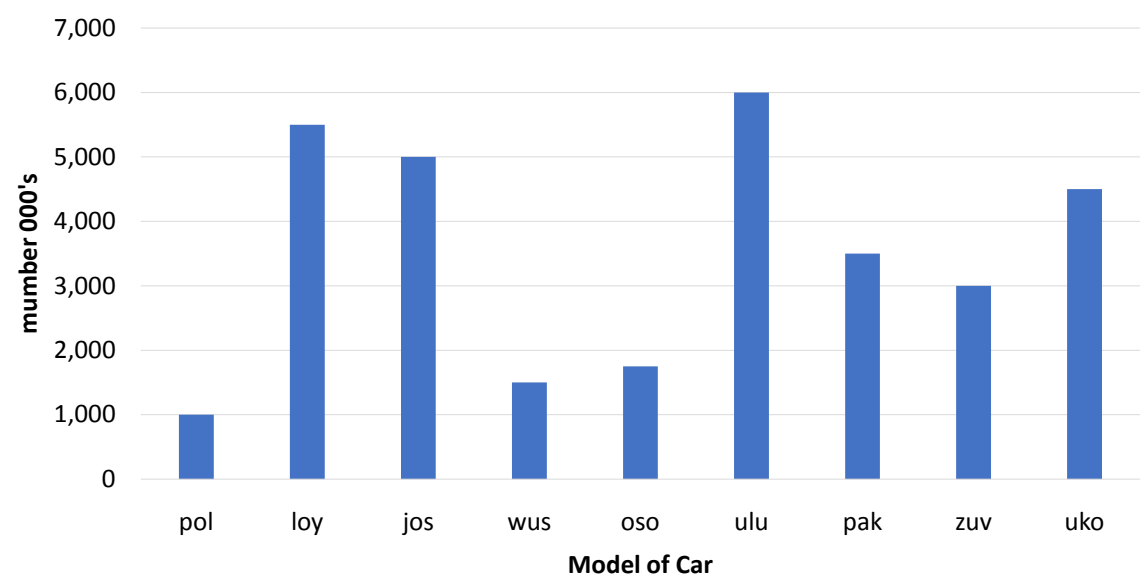

Figure 5. Number of cars sold.

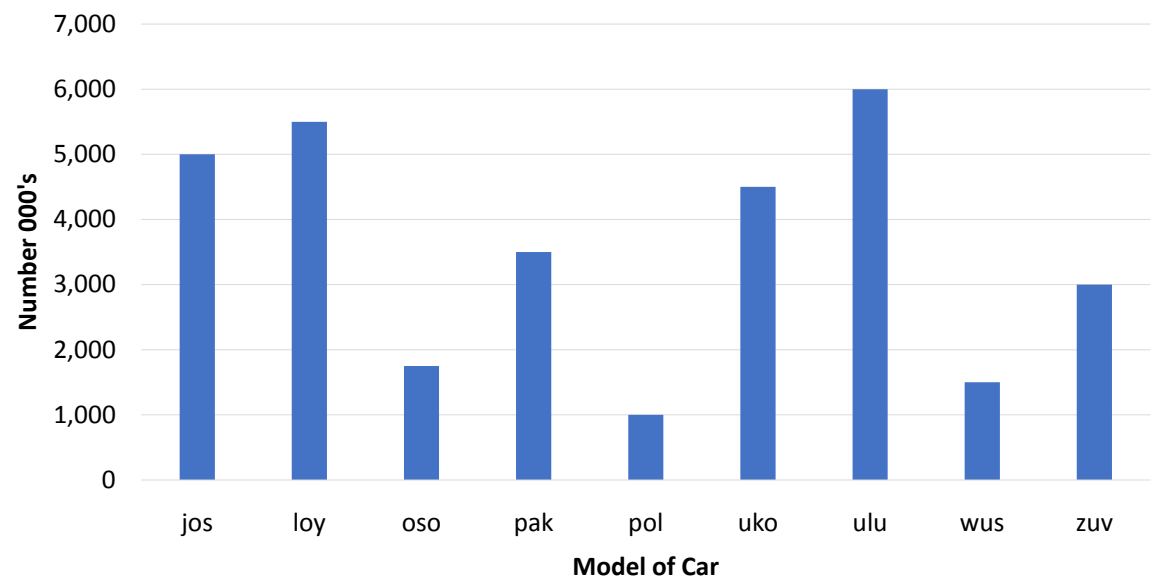

Figure 6. Number of cars sold alphabetically.

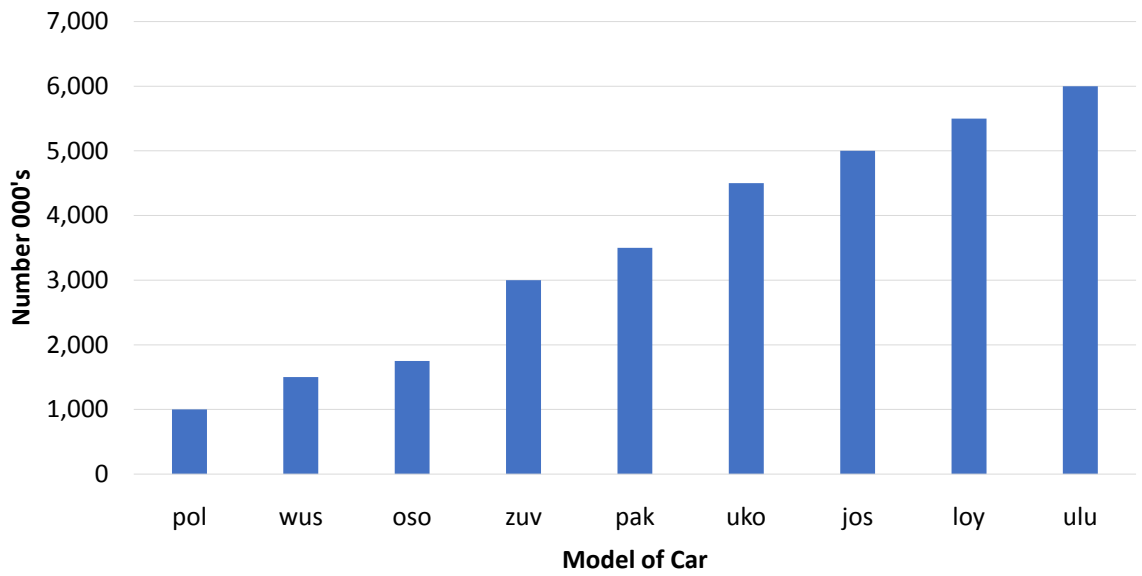

Figure 7. Number of cars sold least-most.

The data can still be represented in other variations that will imply different models to fit the data set. The data can be organized in different wavy forms. Figure 9 shows an example of organizing the data in a wavy form, the model with the largest sales is in the center and data spreads out such that smallest 


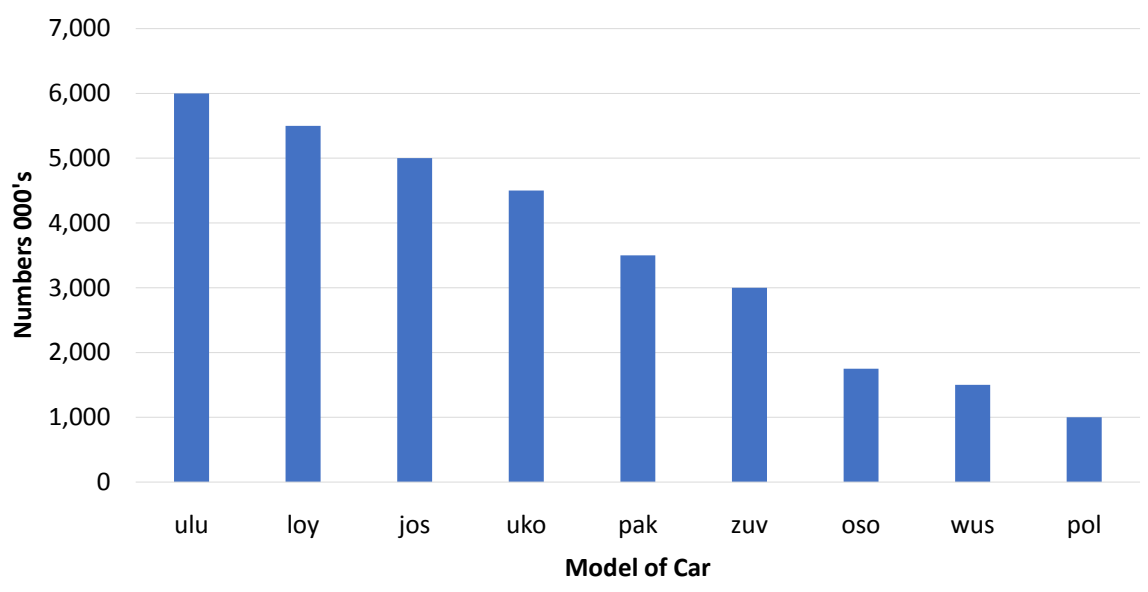

Figure 8. Number of cars sold most-least.

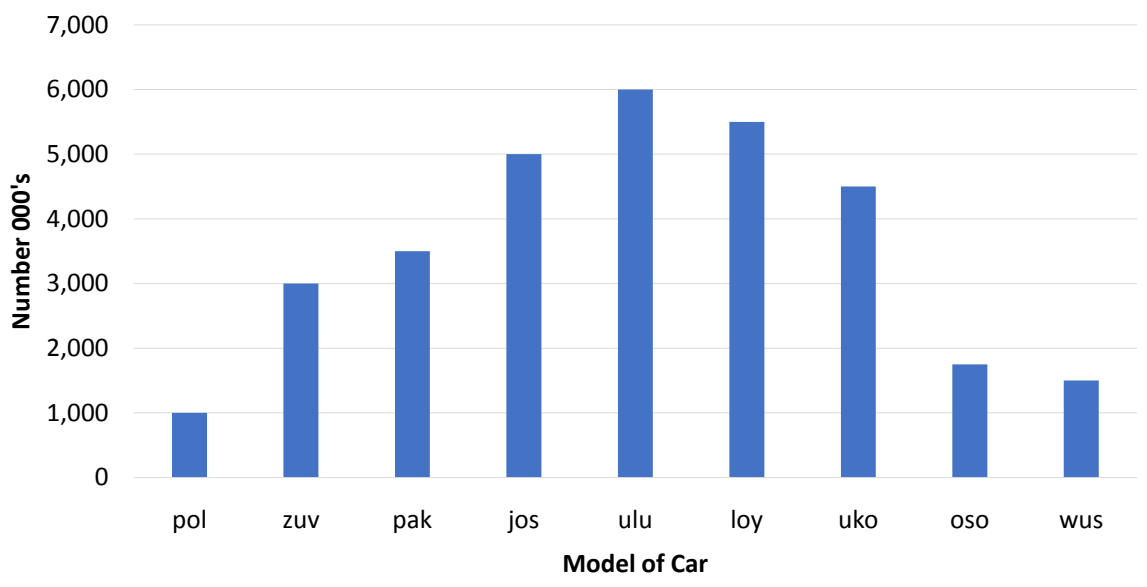

Figure 9. Number of cars sold wavy.

values are at either end. This wavy organization can be organized in several different ways Figure 9 is just one way of organizing data in a wavy fashion.

The wavy form is how nature mostly illustrates data patterns. Take the height of human beings, it is distributed in a wavy form, the normal distribution, but one can organize car sales in a wavy distribution. There are many distribution patterns available to a statistician. Figure 10 shows data in Table 1 organized in a wavy form and illustrated in a wavy form. This wavy form can be shown as a wave as in Figure 10.

Figure 10 is Figure 9, only difference is number of cars sold is shown as shades of color, with the highest car model having the darkest shade and the models that sold the least having the lightest shade. The difference between Figure 10 and Figure 9 is that Figure 6 illustrates intensity at a visual level.

Figure 10 as illustrated above is meant to be just that an illustration. If it was really to mimic reality, shading would be such that the highest value would have the darkest shade, and the lowest value the lightest shade. The shades in-between would get darker and darker such that the darkness corresponds to the number, it would be a needier method of presenting data. Say highest shade is 100 , the 


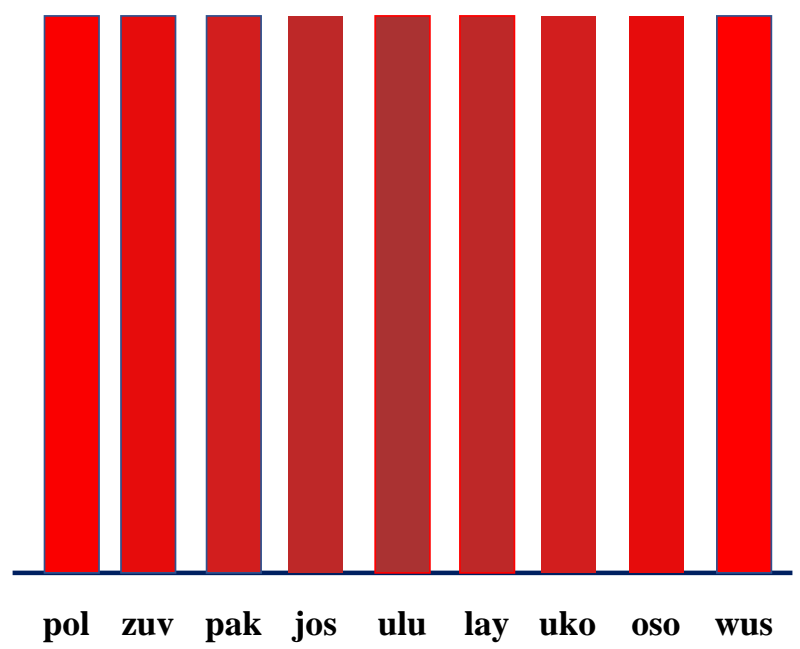

Figure 10. Number of cars sold wave.

lowest shade is 50 , then each degree of shade getting darker illustrates increasing figures, a different number in the tally.

Figure 10 must be included for those who desire to understand similarities of information at the most basic of levels. What does it tell us about human behaviour, after all what tells us what model sold more is the shade of the color, rather than height of the bar, all the bars are of the same height? This tells us that nature outside the human being, we say outside the human being because the human being is part of nature, but events outside the human being, wind, sunshine, full moon, black holes, these do not affect how a human decides, nature leaves all choices open to the human. It is the human who must decide, and that decision is determined by the characteristics of that human being. It is the characteristics of the human that make him/her choose which model. These may include what car is for, is it first car or spare car, how much wealth does individual have, how much income does individual have, is the design appealing, many factors go into the characteristics of the human being.

Not everyone can just purchase a motor vehicle everyday, once a car is purchased one must live with that relationship for some time. The relationship costs energy, that represents a loss of freedom. To merely establish a relationship with a car, an individual must "fork" out a lot of money. That money represents energy, it took time to acquire, no matter the amount it took time to acquire, time doing an activity represents energy spent, that energy spent is rewarded by money such that one can go and purchase food, to acquire more energy. When one purchases a car, that is the characteristics they have at that moment. Thus, when you purchase a Cadillac for $\$ 100,000$ and the richest man in the world does the same, at that moment you have the same characteristics, actions can never lie, you purchased a car for $\$ 100,000$ just like the richest man in the world.

We see this behaviour with basic information, with particles. It was mentioned above that Figure 6 is for those interested in understanding information, accepting that information is everything, and everything has basic characteristics 
that are similar. If one is aware of the double slit experiment, light behaves as a particle and as a wave depending on if it is being observed or not. In both instances how it behaves, its choices are limited. Though it is accepted for now that light is distributed in a wave pattern when observed, the choices that are available to light are limited, where it can go must fall into one of the discrete choices available. The light shining in one's room can't have the possibility of being everywhere, it has a limited amount of discrete choices available depending on its characteristics, just as humans have a limited amount of choices available, and humans choose according to their characteristics. In the example choices are evidently limited to 9 models.

\section{Conclusions}

Human beings will spend their time and energy on an activity that they believe will give them maximum satisfaction, and maximum utility giving their characteristics. When utility is maximized, a rational decision has been made; the first sign that a decision is rational is that one is not starving. If a society faces starvation, it has reached some points whereby past decisions have been caught up and have turned out to be irrational. Economics after all has everything to do with a society not making decisions that will lead to an irrational future.

Choices being limited is not unique to humans, and applies to all information to be a rock, zebra, star, influenza virus, photons, volcanic lava, seeds, anything that one can think of. Not all the seeds become giant baobab trees, and most indeed will be destroyed; not all the salmon will mate; and not all the salmon hatchlings will make it back to the ocean from the source of the river. Choices lead to paths in life; they can be considered choosing a path. Choices will always reflect the characteristic of that piece of information at the moment the path was taken. When the wind blows the seeds, it does not blow all seeds in the same manner that they shall reach a patch that will give them maximum chances of becoming a mature plant. Most seeds are in the wrong place making their paths more difficult. The healthiest of seed biologically might be in the most unfortunate of places physically; location is part of characteristics of a piece of information. What discrimination does a piece of information face is part and parcel of the characteristics of that piece of information; it would act differently without those discriminations.

This argument around rationality would be impossible without the algorithm of information, as it shows that for every question the answer is a probability. Knowledge economics follows the principles of the algorithm of information thus linking it to all other disciplines as all other disciplines are dealing with information and thus the principles of the algorithm of information can never be escaped. In that regards knowledge economics is important because without knowledge economics we would not have the understanding of such a concept. Knowledge economics is important that it shows the algorithm of information but as the algorithm of information is common to all disciplines it is not a ne- 
cessary route to get to the algorithm of information [4].

Understanding that choices are limited and are determined by probability and that choices make one believe to yield a rational expectation, we realize an important factor about economics. The chances of business success are very low, and $75 \%$ of American business start-ups fail within the first year [10]. Therefore, according to probability, it is much riskier to be a business person, which means to start though one hopes for a rational result, they will most likely get an irrational result. How many inventions are successful? Again extremely low probabilities. But inventions drive economic growth in many ways; thus the people involved in such endeavors are more likely to be disappointed, and should statistically be considered irrational. Yet this statistically irrational behaviour leads to economic growth, a rational outcome. To appreciate this one should read Schumpter's [11] ideas on creative destruction in "Capitalism, Socialism and Democracy". Thus, any ideology to be successful must consider this fact that this irrational behaviour leads to a rational outcome for society. Irrational expectations drive development, which is a result of fulfilling what initially would be considered irrationality statistically.

Knowledge economics could readily understand the algorithm of information because it came from knowledge, came from a thought pattern that included the human being, and understood that in any thought the human being can never be taken out.

The idea of everything being information comes from quantum mechanics [12], a term that needed a lot of experiments to define properly, everything can compute, a fact that can digitize everything, a fact that confirms the discreteness of everything. Knowledge economics at the very least has its roots in a scientific thought that is common to all disciplines, that everything is information so even though it accepts specialization it does not separate itself, this is something that obviously should be common to all information. Every discipline is separate in that it has its own unique way of understanding information; however, it remains information being looked into, and by that fact we realize every discipline is dealing with probability, every discipline utilizes statistics as a tool (not forgetting nothing is continuous everything is discrete all information is), if you do this then this likely will happen, but as former heavyweight champion Mike Tyson said, "everybody has a plan until they are hit". Drucker [13] didn't understand everybody is using knowledge, he didn't understand information, everybody uses knowledge to survive, all are knowledge workers. At the end of the day everything is routine, the inventor goes to his desk every day, doing the same thing, looking for what works, that is his routine, the shovellor goes and shovels everyday go back to the dictionary. Drucker should have thought of a better word for the category of worker, not knowledge, it held back developing knowledge to what it truly is.

At the end of the day looking at things as knowledge cuts out unnecessary distance amongst disciplines, humans are part of everything, the question is not 
why do humans exist, it is why does anything exist, to answer a question? Questions we part answer every day by our choices, each choice being an answer to a question, should I, should I wake up?

\section{References}

[1] Bellis, M. (2017). Who Invented the Microchip. https://www.thoughtco.com/what-is-a-microchip-1991410

[2] Khumalo, B. (2016) Why Economics Is a Science: Information, the Grand Unifier. Modern Economy, 7, 183-193. https://doi.org/10.4236/me.2016.72020

[3] Khumalo, B. (2012) Defining Economics in the Twenty First Century. Modern Economy, 3, 597-607. https://doi.org/10.4236/me.2012.35079

[4] Khumalo, B. (2007) Point X and the Economics of Knowledge. https://ideas.repec.org/p/pra/mprapa/3735.html

[5] Hori, S. and Sato, E. (2015) Materials Engineer = Merchant of Death? http://www.isas.jaxa.jp/en/feature/forefront/150930.html

[6] Kotkin (2017) When Stalin Faced Hitler. Foreign Affairs, November December, 48-71.

[7] Khumalo, B. (2016) The Theory of Everything: Newton, Information, Complexity, and Evolution.

http://instituteofknowledge.blogspot.ca/2016/11/the-theory-of-everything-newton.h $\underline{\mathrm{tml}}$

[8] Staff (2011) Wolf Reintroduction Changes Ecosystem. https://www.yellowstonepark.com/things-to-do/wolf-reintroduction-changes-ecosy $\underline{\text { stem }}$

[9] Khumalo, B. (2009) The Variable Time: Crucial to Understanding Knowledge Economics. http://www.iupindia.in/109/IJKM_Knowledge_Economics_34.html

[10] Henry, P. (2017) Why Some Startups Succeed (and Why Most Fail). https://www.entrepreneur.com/article/288769

[11] Schumpeter, J.A. (1942) Capitalism, Socialism, and Democracy. Harper and Brothers, New York London.

[12] Muon, R. (2015) Physics of Information-Quantum Entanglement, Black Holes and Holographic Universe.

[13] Drucker, P. (1959) The Landmarks of Tomorrow. Harper and Row, New York. 